\title{
Screening for gestational diabetes mellitus in a South African population: Prevalence, comparison of diagnostic criteria and the role of risk factors
}

\author{
S Adam, ${ }^{1}$ MB ChB, FCOG (SA), MMed (O\&G), Cert Maternal Fetal Medicine (SA); P Rheeder, MB ChB, MMed (Int Med), FCP (SA), \\ $\mathrm{MSc}$ (Clin Epidemiol), $\mathrm{PhD}$
}

\author{
${ }^{1}$ Department of Obstetrics and Gynaecology, School of Medicine, Faculty of Health Sciences, University of Pretoria, South Africa \\ ${ }^{2}$ Department of Internal Medicine, School of Medicine, Faculty of Health Sciences, University of Pretoria, South Africa
}

Corresponding author: S Adam (sumaiya.adam@up.ac.za)

\begin{abstract}
Background. The prevalence of gestational diabetes mellitus (GDM) is increasing. Most major world organisations now recommend universal screening for GDM based on the International Association of Diabetes in Pregnancy Study Groups (IADPSG) criteria. Currently there is a lack of consensus on the diagnostic criteria for GDM used in South Africa (SA). The Society for Endocrinology, Metabolism and Diabetes of South Africa's revised guidelines recommend the use of the IADPSG criteria for the diagnosis of GDM.

Objectives. To determine the prevalence of GDM in an SA population. We compared the prevalence of GDM using the various diagnostic criteria and evaluated the risk factors associated with GDM.

Methods. This was a prospective cohort observational study carried out at a level 1 clinic in Johannesburg, SA. All pregnant women at $<26$ weeks' gestation were recruited. Patients known to have GDM were excluded. At recruitment, a data questionnaire was completed and bloods were drawn for a random glucose test and measurement of the glycated haemoglobin level. A $75 \mathrm{~g}$ 2-hour oral glucose tolerance test (OGTT) was scheduled before 28 weeks' gestation.

Results. Five hundred and fifty-four patients (55.4\%) completed the OGTT. The prevalence of GDM was $25.8 \%$ if universal screening and the IADPSG criteria were used. If universal screening and the National Institute for Health and Care Excellence (NICE) criteria were used, the prevalence was $17.0 \%$. If selective risk factor-based screening was used, only 254 (45.8\%) of the women would have had an OGTT. The prevalence of GDM in this instance would have been $15.2 \%$ with the IADPSG criteria and $3.6 \%$ with the NICE criteria. Two hundred and fifty-four patients ( $45.8 \%$ ) had at least one risk factor for GDM. The presence of one or more risk factors had a poor sensitivity (58.7\%) and specificity (58.6\%) for the detection of GDM in our study population.

Conclusions. The prevalence of GDM would be substantially increased if universal screening with the IADPSG criteria were to be employed. Risk factors are a poor screening test for GDM.
\end{abstract}

S Afr Med J 2017;107(6):523-527. DOI:10.7196/SAMJ.2017.v107i6.12043

Globally there is an alarming increase in the incidence of type 2 diabetes mellitus (DM) and obesity. South Africa (SA) is now regarded as one of the world's most obese nations. ${ }^{[1]}$ Pregnancy is characterised by insulin resistance and hyperinsulinaemia, predisposing some women to develop gestational DM (GDM). It is well recognised that women who develop GDM in pregnancy are at an increased risk of pregnancy complications as well as DM in later life. In addition, poor glycaemic control in pregnancy impacts adversely on neonatal outcome and puts the child at increased risk of developing obesity and DM. ${ }^{[2]}$

Over the decades, global organisations have recommended a plethora of algorithms for the screening and diagnosis of GDM. In 2010, the International Association of Diabetes in Pregnancy Study Groups (IADPSG) proposed consensus-derived cut-off values for the diagnosis of GDM. Their thresholds were derived from the 1.75 increase in odds of having a complication in pregnancy based on the Hyperglycemia and Adverse Pregnancy Outcomes (HAPO) study population. The IADPSG criteria have now been adopted by the International Federation of Gynecology and Obstetrics and most international organisations, with the American Congress of Obstetricians and Gynecologists and the National Institute for Health and Care Excellence (NICE) being notable exceptions. ${ }^{[3]}$
The prevalence of GDM in SA is estimated to be $1.6-8.8 \%$ based on scant data and selective risk factor-based screening. ${ }^{[4]}$ While it is well known that women with GDM have certain definable risk factors, there is concern that a significant proportion of women with GDM will be missed if screened by risk factors alone, as has been illustrated in numerous studies. ${ }^{[5-7]}$ Current international opinion favours the universal screening of all pregnant women for GDM, where local circumstances allow.

Screening for and diagnosis of GDM in SA remain disorderly. There are disparities in protocols between provinces and hospitals. In 2012, the Society for Endocrinology, Metabolism and Diabetes of South Africa (SEMDSA) recommended risk factor-based selective screening at $24-28$ weeks' gestation using the World Health Organization (WHO) 1999 criteria. ${ }^{[8]}$ Risk factors include advanced maternal age, obesity, a family history of DM, previous adverse pregnancy outcome (congenital abnormality, recurrent miscarriages, delivery of a stillborn child), delivery of a macrosomic baby in a previous pregnancy, certain ethnic backgrounds, or significant or persistent glycosuria. The society's new guidelines will recommend universal screening, according to which all pregnant women will be screened for GDM with the IADPSG criteria ( $\mathrm{Z}$ Bayat, personal communication, September 2016). At present, risk factor-based 
selective screening is the predominant practice in SA. The most commonly used diagnostic criteria in SA are the NICE, IADPSG and WHO 1999 criteria. However, each centre has decided independently on which diagnostic criteria to use. In Pretoria, the IADPSG criteria ${ }^{[3]}$ are used, Johannesburg uses the NICE criteria, ${ }^{[3]}$ while the Western Cape Province uses a combination of the Western Cape criteria ${ }^{[9]}$ and the NICE guidelines. ${ }^{[3]}$ The variation in diagnostic criteria used results in discrepancies in prevalence and the women classified as having GDM. This results in many women with GDM not receiving appropriate treatment.

\section{Objectives}

To determine the prevalence of GDM in an SA population. We compared the prevalence of GDM using the various diagnostic criteria, and also evaluated the risk factors associated with GDM.

\section{Methods}

This research was part of a larger study investigating screening strategies for GDM in an SA population. We carried out a prospective cohort observational study at a level 1 clinic in Johannesburg. One thousand pregnant women at $<26$ weeks' gestation were recruited. Patients known to have GDM and those who were $\geq 26$ weeks pregnant were excluded. Gestational age was based on the patient's last normal menstrual period, an ultrasound scan or palpation of the symphysis-fundal height.

At recruitment, the women completed a questionnaire including demographic data and an evaluation of risk factors for GDM. A random glucose test was done and the glycated haemoglobin (HbAlc) level measured. If the random glucose level was $>11.1 \mathrm{mmol} / \mathrm{L}$ or the $\mathrm{HbAlc}$ level $>6.5 \%$, the patient was referred to the local hospital for further management of DM. Otherwise, a $75 \mathrm{~g}$ 2-hour oral glucose tolerance test (OGTT) was scheduled for between 24 and 28 weeks' gestation. At the time of the OGTT, HbAlc was measured again. All blood was drawn by a registered nurse and stored on ice until it was delivered to the laboratory on the same day.

The diagnosis of GDM was compared using the diagnostic criteria set out in Table 1.

\section{Statistical analysis}

The data were analysed using the Stata 13 statistical package (StataCorp, USA). Descriptive statistics were used to describe the population. Student's $t$-test was calculated for continuous variables and the $\chi^{2}$ test for categorical data. The presence of any one risk factor was considered a positive finding. Risk factors considered were obesity (body mass index (BMI) $\geq 30 \mathrm{~kg} / \mathrm{m}^{2}$ ), age $\geq 35$ years, delivery of a baby weighing $\geq 4000 \mathrm{~g}$ in a previous pregnancy, glycosuria, a history of GDM in a previous pregnancy, or a history of a baby with a congenital abnormality, an unexplained stillbirth, or recurrent pregnancy losses. The sensitivity and specificity for having at least one risk factor as a screening tool for GDM was calculated. The

\begin{tabular}{lllll}
\multicolumn{4}{l}{ Table 1. Diagnostic criteria for GDM commonly used in SA } \\
\hline $\begin{array}{l}\text { Glucose } \\
\text { level } \\
(\mathbf{m m o l} / \mathrm{L})\end{array}$ & IADPSG & NICE & $\begin{array}{l}\text { WHO } \\
\text { 1999 }\end{array}$ & Western Cape \\
\hline $0 \mathrm{~h}$ & 5.1 & 5.6 & 7.0 & Random glucose $8-11$ \\
$1 \mathrm{~h}$ & 10 & $\mathrm{n} / \mathrm{a}$ & $\mathrm{n} / \mathrm{a}$ & $\mathrm{mmol} / \mathrm{L} \rightarrow$ fasting glucose \\
$2 \mathrm{~h}$ & 8.5 & 7.8 & 7.8 & $\begin{array}{l}\text { Fasting glucose } \geq 6 \mathrm{mmol} / \mathrm{L} \\
\end{array}$ \\
& & & & $\rightarrow$ for glucose profile
\end{tabular}

$\mathrm{GDM}=$ gestational diabetes mellitus; $\mathrm{SA}=$ South Africa; $\mathrm{IADPSG}=$ International = Association of Diabetes in Pregnancy Study Groups; NICE $=$ National Institute for
and Care Excellence; WHO = World Health Organization; $\mathrm{n} / \mathrm{a}=$ not applicable. statistical significance level and the confidence interval were set at $p<0.05$ and $95 \%$, respectively.

\section{Ethics approval}

Approval for the study was obtained from the Faculty of Health Sciences Ethics Committee, University of Pretoria (ref. no. 180/2012). Written informed consent was obtained from each patient prior to enrolment into the study. Participants were provided with an information leaflet on gestational diabetes.

\section{Results}

One thousand pregnant women were recruited. Eighty-two women (8.2\%) had fetal losses and did not continue with the study, 163 (16.3\%) moved away from the area and were therefore lost to followup, $194(19.4 \%)$ were unreachable and 7 (0.7\%) withdrew consent. Five hundred and fifty-four women (55.4\%) therefore had complete data available for analysis.

The clinical and biochemical characteristics of the women with and without GDM based on the IADPSG criteria are given in Table 2. The mean age, weight, BMI, HbAlc level at recruitment and random glucose level at recruitment were significantly higher in women with GDM compared with those without.

All the women would have had an OGTT if universal screening had been employed, and only 254 (45.8\%) would have had one if selective risk factor-based screening had been employed. The prevalence of GDM based on the different diagnostic criteria is illustrated in Figs 1 and 2. The prevalence was $25.8 \%$ with universal screening and $15.2 \%$ with selective screening when the IADPSG criteria were used.

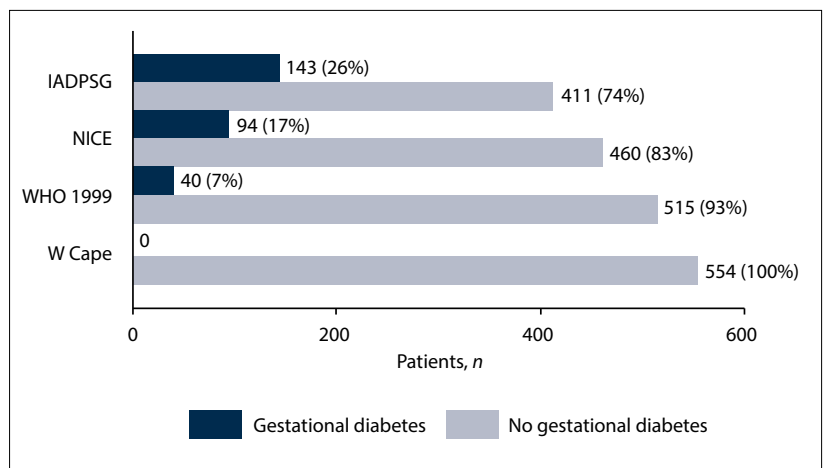

Fig. 1. Prevalence of GDM based on universal screening. (IADPSG $=$ International Association of Diabetes in Pregnancy Study Groups; NICE = National Institute for Health and Care Excellence; $W H O=$ World Health Organization; $W$ Cape = Western Cape.)

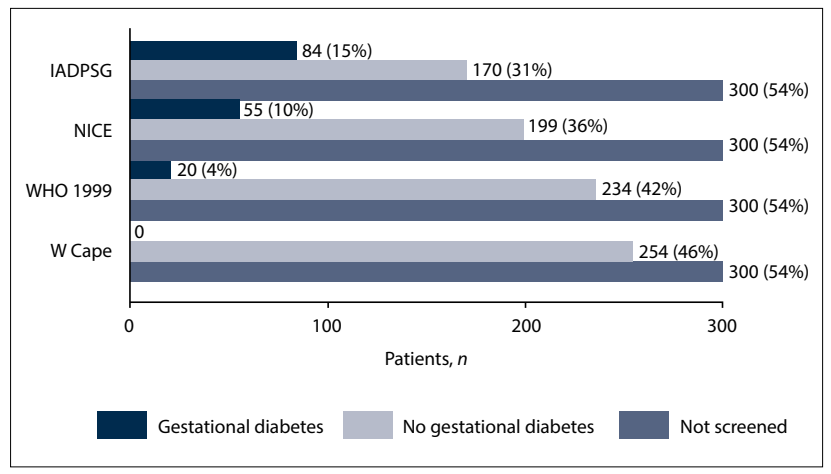

Fig. 2. Prevalence of GDM based on selective screening. (IADPSG = International Association of Diabetes in Pregnancy Study Groups; NICE = National Institute for Health and Care Excellence; $W H O=$ World Health Organization; $W$ Cape = Western Cape.) 


\begin{tabular}{|c|c|c|c|}
\hline Variable & No GDM $(N=411)$ & GDM $(N=143)$ & $p$-value \\
\hline Age (yr), mean (range) & $26.8(15-42)$ & $28.4(13-42)$ & 0.004 \\
\hline Weight $(\mathrm{kg})$, mean (range) & $68.5(42.9-124)$ & $72.1(45.3-122.2)$ & 0.010 \\
\hline Height (m), mean (range) & $1.65(14.8-46.2)$ & $1.62(1.47-1.78)$ & 0.590 \\
\hline BMI $\left(\mathrm{kg} / \mathrm{m}^{2}\right)$, mean (range) & $26.1(1.45-1.82)$ & $27.9(17.5-47.2)$ & 0.001 \\
\hline MUAC (cm), mean (range) & $28.5(18-42)$ & $29.8(17-45)$ & 0.003 \\
\hline Parity, mean (range) & $1.05(0-4)$ & $1.2(0-5)$ & 0.096 \\
\hline $\mathrm{Hb}(\mathrm{g} / \mathrm{dL})$, mean (range) & $12.3(6.1-17.2)$ & $12.5(7.5-16.1)$ & 0.370 \\
\hline \multicolumn{4}{|l|}{ HbAlc (\%), mean (range) } \\
\hline Booking & $5.1(3.8-6.3)$ & $5.3(4.1-6.5)$ & 0.001 \\
\hline OGTT & $5.1(4.0-7.7)$ & $5.6(4.4-6.4)$ & 0.027 \\
\hline \multicolumn{4}{|c|}{ Random glucose (mmol/L), mean (range) } \\
\hline Capillary & $4.6(2.3-8.6)$ & $4.7(2.8-9.0)$ & 0.565 \\
\hline Laboratory & $4.5(2.9-9.3)$ & $4.7(3.3-6.5)$ & 0.002 \\
\hline \multicolumn{4}{|c|}{ Fasting glucose $(\mathrm{mmol} / \mathrm{L})$, mean (range) } \\
\hline Capillary & $4.3(2.8-6.3)$ & $4.6(2.7-8.4)$ & 0.000 \\
\hline Laboratory & $4.4(2.1-4.9)$ & $5.8(3.9-13.4)$ & 0.000 \\
\hline \multicolumn{4}{|c|}{ OGTT, 1-hour glucose $(\mathrm{mmol} / \mathrm{L})$, mean (range) } \\
\hline Capillary & $6.4(2.6-12.9)$ & $7.0(3.6-11.2)$ & 0.000 \\
\hline Laboratory & $5.6(1.7-9.9)$ & $6.7(3.9-12.1)$ & 0.000 \\
\hline \multicolumn{4}{|c|}{ OGTT, 2-hour glucose $(\mathrm{mmol} / \mathrm{L})$, mean (range) } \\
\hline Capillary & $5.8(3.3-10.4)$ & $6.4(4.4-15.5)$ & 0.000 \\
\hline Laboratory & $5.2(1.8-8.4)$ & $6.5(3.4-13.8)$ & 0.000 \\
\hline \multicolumn{4}{|l|}{ HIV, $n(\%)$} \\
\hline Negative & $296(72.0)$ & $93(65.0)$ & \\
\hline Positive & $111(27.0)$ & $49(34.3)$ & 0.252 \\
\hline Unknown & $4(1.0)$ & $1(0.7)$ & \\
\hline Anaemia $(\mathrm{Hb}<11 \mathrm{~g} / \mathrm{dL}), n(\%)$ & $N=324$ & $N=122$ & \\
\hline No & $245(75.6)$ & $104(85.2)$ & 0.500 \\
\hline Yes & $79(24.4)$ & $18(14.8)$ & \\
\hline \multicolumn{4}{|c|}{ Hypertension (BP >135/85 mmHg), $n(\%)$} \\
\hline No & $311(75.7)$ & $94(65.7)$ & 0.210 \\
\hline Yes & $100(24.3)$ & $49(34.3)$ & \\
\hline Education, $n(\%)$ & $N=394$ & $N=141$ & \\
\hline < grade 12 & $231(58.6)$ & $81(57.4)$ & 0.807 \\
\hline$\geq$ grade 12 & $163(41.4)$ & $60(42.6)$ & \\
\hline Employment, $n(\%)$ & $N=408$ & $N=142$ & \\
\hline Unemployed & $257(63.0)$ & $73(51.4)$ & \\
\hline Employed & $144(35.3)$ & $64(45.1)$ & 0.037 \\
\hline Scholar & $7(1.7)$ & $5(3.5)$ & \\
\hline \multicolumn{4}{|l|}{ Risk factors, $n(\%)$} \\
\hline 0 & $241(58.6)$ & $59(41.3)$ & 0.000 \\
\hline$\geq 1 \quad(n=254)$ & $170(41.4)$ & $84(58.7)$ & 0.000 \\
\hline
\end{tabular}

GDM = gestational diabetes mellitus; IADPSG = International Association of Diabetes in Pregnancy Study Groups; BMI = body mass index; MUAC = mid-upper arm circumference; $\mathrm{Hb}=$ haemoglobin; $\mathrm{HbAlc}=$ glycated haemoglobin; $\mathrm{OGTT}=$ oral glucose tolerance test; $\mathrm{BP}=$ blood pressure

If we used the NICE criteria and universal screening the prevalence was $17.0 \%$. If selective screening was used, the prevalence was $3.6 \%$. With the WHO 1999 criteria, the prevalence of GDM was 7.2\% with universal screening and $3.6 \%$ with selective screening. The Western Cape criteria would have diagnosed no woman in our study population as having GDM.

Table 3 illustrates the differences between patients who had GDM based on either the IADPSG criteria or the NICE criteria. There were significant differences in age, weight, BMI, $\mathrm{HbAlc}$ at booking and at the time of the OGTT, random and fasting glucose, and the number of patients with at least one risk factor for GDM.
In our study, 254 patients (45.8\%) had at least one risk factor for GDM. Of these, $26.0 \%$ had GDM. However, the presence of one or more risk factors had a poor sensitivity $(58.7 \%)$ and specificity (58.6\%) for the detection of GDM in our study population (Table 4). The positive likelihood ratio was 1.42 and the negative likelihood ratio 0.704 . Risk factors had a positive predictive value of $33.1 \%$, a negative predictive value of $80.3 \%$ and an odds ratio of 2.02 .

\section{Discussion}

The objective of this study was to determine the prevalence of GDM and its associated risk factors in an SA population. To our 


\begin{tabular}{|c|c|c|c|}
\hline Variable & IADPSG $(N=143)$ & NICE $(N=94)$ & $p$-value \\
\hline Age (years), mean (range) & $28.4(13-42)$ & $28.7(13-42)$ & 0.010 \\
\hline Weight (kg), mean(range) & $72.1(45.3-122.2)$ & $75.5(45.3-122.2)$ & 0.030 \\
\hline Height (m), mean (range) & $1.62(1.47-1.78)$ & $1.61(1.47-1.76)$ & 0.850 \\
\hline BMI $\left(\mathrm{kg} / \mathrm{m}^{2}\right)$, mean (range) & $27.9(17.5-47.2)$ & $28.3(17.5-47.2)$ & 0.000 \\
\hline MUAC (cm), mean (range) & $29.8(17-45)$ & $30.0(20-45)$ & 0.010 \\
\hline Parity, mean (range) & $1.2(0-5)$ & $1.3(0-5)$ & 0.060 \\
\hline $\mathrm{Hb}(\mathrm{g} / \mathrm{dL})$, mean (range) & $12.5(7.5-16.1)$ & $12.5(8.3-15.7)$ & 0.570 \\
\hline \multicolumn{4}{|l|}{ HbAlc (\%), mean (range) } \\
\hline Booking & $5.3(4.1-6.5)$ & $5.3(4.2-6.5)$ & 0.000 \\
\hline OGTT & $5.6(4.4-6.8)$ & $5.9(4.4-6.8)$ & 0.020 \\
\hline \multicolumn{4}{|c|}{ Random glucose (mmol/L), mean (range) } \\
\hline Capillary & $4.7(2.8-9.0)$ & $4.7(2.8-9.0)$ & 0.750 \\
\hline Laboratory & $4.7(3.3-6.5)$ & $4.7(3.3-9.3)$ & 0.000 \\
\hline \multicolumn{4}{|c|}{ Fasting glucose $(\mathrm{mmol} / \mathrm{L})$, mean (range) } \\
\hline Capillary & $4.6(2.7-8.4)$ & $4.6(2.7-8.4)$ & 0.000 \\
\hline Laboratory & $5.8(3.9-13.4)$ & $6.0(3.9-13.4)$ & 0.000 \\
\hline HIV, $n(\%)$ & & $N=103$ & \\
\hline Negative & $93(65.0)$ & $66(70.2)$ & \\
\hline Positive & $49(34.3)$ & $28(29.8)$ & 0.080 \\
\hline Unknown & $1(0.7)$ & $0(0)$ & \\
\hline Anaemia $(\mathrm{Hb}<11 \mathrm{~g} / \mathrm{dL}), n(\%)$ & $N=122$ & $N=75$ & \\
\hline No & $104(85.2)$ & $65(86.7)$ & 0.080 \\
\hline Yes & $18(14.8)$ & $10(13.3)$ & \\
\hline \multicolumn{4}{|c|}{ Hypertension (BP >135/85 mmHg), $n(\%)$} \\
\hline No & $94(65.7)$ & $61(64.9)$ & 0.060 \\
\hline Yes & $49(34.3)$ & $33(35.1)$ & \\
\hline Education, $n(\%)$ & $N=141$ & $N=93$ & \\
\hline < grade 12 & $81(57.4)$ & $53(57.0)$ & 0.210 \\
\hline$\geq$ grade 12 & $60(42.6)$ & $40(43.0)$ & \\
\hline Employment, $n(\%)$ & $N=142$ & $N=93$ & \\
\hline Unemployed & $73(51.4)$ & $53(57.0)$ & 0.080 \\
\hline Employed & $64(45.1)$ & $36(38.7)$ & \\
\hline Scholar & $5(3.5)$ & $4(4.3)$ & \\
\hline \multicolumn{4}{|l|}{ Risk factors, $n(\%)$} \\
\hline 0 & $59(41.3)$ & $39(41.5)$ & 0.000 \\
\hline$\geq 1$ & $84(58.7)$ & $55(58.5)$ & \\
\hline
\end{tabular}

Table 4. Performance of risk factors as a screening tool for GDM

\begin{tabular}{llll}
\hline & \multicolumn{2}{c}{ Risk factors $\geq \mathbf{1}$} & \\
\cline { 2 - 3 } & \multicolumn{1}{c}{ Yes } & No & Total \\
\hline GDM, $n(\%)$ & & & \\
$\quad$ Yes & $84(15.2)$ & $59(10.6)$ & $143(25.8)$ \\
No & $170(30.7)$ & $241(43.5)$ & $411(74.2)$ \\
Total, $n(\%)$ & $254(45.8)$ & $300(54.2)$ & $554(100)$ \\
GDM $=$ gestational diabetes mellitus. & & & \\
& & &
\end{tabular}

knowledge, this is the first study to evaluate the IADPSG criteria in an SA population.

Screening for GDM in SA is chaotic. In 2012, SEMDSA recommended risk factor-based selective screening using the WHO 1999 criteria. ${ }^{[8]}$ The society's new guidelines recommend universal screening with the IADPSG criteria (personal communication). This change in recommendation would translate to a $>100 \%$ increase in the number of pregnant women who would need to be screened, and a 7.2 -fold increase in the prevalence of GDM from $3.6 \%$ to $25.8 \%$.
The incidence of GDM is increasing worldwide. The IADPSG diagnostic criteria were extrapolated from the population screened in the HAPO study. Although there was no clear inflection point above which the adverse effects of GDM increased, the IADPSG recommends diagnostic criteria based on an odds ratio of $1.75 .{ }^{[3,10]}$ When these criteria were applied to the HAPO population, a GDM prevalence of $18 \%$ was found. However, a GDM prevalence of $25.8 \%$ was found in our study population when the IADPSG criteria were used. This markedly increased prevalence of GDM found with the IADPAG criteria is greater than the prevalence found in other countries. ${ }^{[3]}$

The significant increase in the prevalence of GDM reported in this study compared with previous SA studies can be attributed to the lower diagnostic threshold and the use of universal screening. ${ }^{[4]}$ The IADPSG criteria were used because they are now recommended in an attempt to standardise the diagnosis of GDM globally ${ }^{[3]}$ and are recommended in the proposed SEMDSA guidelines.

Changes in lifestyle in SA have contributed to the increasing risk of obesity. While modifiable, these changes have contributed to the 
increasing prevalence of DM in the general population. ${ }^{[1]}$ Similarly, obesity is also associated with an increased likelihood of having GDM. It is known that women with GDM are at an almost $50 \%$ increased risk of developing DM within 10 years. The increasing incidence of GDM is of concern, as these women and their offspring are at an increased risk of cardiometabolic disease. It has also been demonstrated that the partners of women with GDM are at increased risk of developing type $2 \mathrm{DM}^{\left[{ }^{[1,12]}\right.}$ There is a need for large-scale awareness and lifestyle modification programmes to alter these risks.

Currently the most widely used criteria for screening for GDM in SA are the NICE guidelines. The NICE criteria appear to be an attractive alternative for the diagnosis of GDM. Their use in this study resulted in a $17.0 \%$ prevalence of GDM. However, this may not be ideal. Meek et al. ${ }^{[13]}$ have found that women who did not have GDM if the NICE criteria were applied but had GDM if the IADPSG criteria were used were still at an increased risk of adverse obstetric outcomes such as an increased caesarean section rate, polyhydramnios and fetal macrosomia.

Risk factor-based screening has been widely utilised to identify women at high risk of having GDM. If we had used selective screening in our study, 59 patients (10.6\%) with GDM would not have been diagnosed if we had used the IADPSG diagnostic criteria, and 39 (7.0\%) if we had used the NICE diagnostic criteria.

Historically risk factor-based selective screening has been recommended for screening for GDM, as it was not considered to be cost-effective to subject all women to laboratory testing. Risk factor-based screening performs poorly as a screening tool for GDM. It has also been found to have poor sensitivity and specificity in other studies. ${ }^{[1,15]}$ Furthermore, a major challenge of selective screening is that it places a high demand on the healthcare worker to identify patients who should be screened. In effect, this results in reduced compliance and inadequate screening and testing.

Universal screening and the low diagnostic threshold proposed by the IADPSG, on the other hand, may have the potential to overdiagnose GDM. This has both financial and workload implications, which have been the subject of much debate. ${ }^{[16]}$

The Western Cape guidelines propose a novel approach to screening for GDM. In our study, no patients were diagnosed with GDM when these criteria were applied. This may be due to the low socioeconomic status of the population in which this study was conducted. Because of poor social circumstances, many pregnant women present to the antenatal clinic without having eaten an adequate breakfast, as can be seen by the similar random and fasting glucose measurements.

Selective screening remains an alluring option for SA. In addition to being a middle- to low-income country, we are faced with a dual burden of disease - malnutrition, poverty and communicable diseases, while obesity and lifestyle-related non-communicable diseases are increasing. However, if we are to consider risk factorbased screening, we would have to define appropriate, simply applied risk factors and evaluate the efficacy of such a strategy.

\section{Study strengths and limitations}

The strengths of this study were that we prospectively assessed the prevalence of GDM and its associated risk factors in a low-risk SA population, and that we applied universal screening and the IADPSG criteria. The limitations are that this was a local study in a black African population and there was a large loss to follow-up.

\section{Conclusions}

Universal screening is the only strategy by which the majority of women with GDM will be diagnosed. There will be a substantial increase in the prevalence of GDM in SA with the use of the IADPSG criteria, regardless of whether universal or selective screening is implemented. We need to investigate and standardise the ideal strategy for screening for GDM in the SA context. Owing to the varied health priorities in this country, it is evident that an appropriate set of diagnostic criteria needs to evolve from a consensus approach based on balancing obstetric and long-term health risks and benefits in our unique socioeconomic and clinical context.

Acknowledgements. The authors acknowledge all research assistants and study participants.

Author contributions. Both authors contributed equally to the compilation of this article.

Funding. This study was partly supported by funding from SEMDSA, the South African Sugar Association and Roche.

Conflicts of interest. None.

1. Sartorius B, Veerman LJ, Manyema M, Chola L, Hofman K. Determinants of obesity and associated population attributability, South Africa: Empirical evidence from a national panel survey, 2008 - 2012 population attributability, South Africa: Empirical evidence from a national panel
PLoS One 2015;10(6):e0130218. http://dx.doi.org/10.1371/journal.pone.0130218

2. Dodd JM, Crowther CA, Antoniou G, et al. Screening for gestational diabetes: The effect of varying . Dodd JM, Crowther CA, Antoniou G, et al. Screening for gestational diabetes: The effect of varying
blood glucose definitions in the prediction of adverse maternal and infant health outcomes. Aust N Z J Obstet Gynecol 2007;47(4):307-312. http://dx.doi.org/10.1111/J.1479-828X.2007.00743.x

3. McIntyre HD, Colagiuri S, Roglic G, Hod M. Diagnosis of GDM: A suggested consensus. Best Pract Res Clin Obstet Gynaecol 2015;29(2):194-205. http://dx.doi.org/10.1016/j.bpobgyn.2014.04.022

4. Macauley S, Dunger DB, Norris SA. Gestational diabetes mellitus in Africa: A systematic review. PLoS One 2014;9(6):e97871. http://dx.doi.org/10.1371/journal.pone.0097871

5. Moses RG, Moses J, Davis WS. Gestational diabetes: Do lean young Caucasian women need to be tested? Diabetes Care 1998;21(11):1803-1806. http://dx.doi.org/10.2337/diacare.21.11.1803

6. Danilenko-Dixon DR, van Winter JT, Nelson RL, Ogburn PL. Universal versus selective screening. Application of 1997 American Diabetes Association recommendations. Am J Obstet Gynecol 1999;181(4):798-802. http://dx. doi.org/10.1016/S0002-9378(99)70304-2

7. Williams CB, Yu DY, Iqbal S, Brown MB, Zawacki CM, Herman WH. Effect of selective screening for gestational diabetes. Diabetes Care 1999;22(3):418-421. http://dx.doi.org/10.2337/DIACARE.22.3.418

8. The 2012 SEMDSA guideline for the management of type 2 diabetes (Revised). J Endocrinol Metab The 2012 SEMDSA guideline for the management of type 2 diabetes (Revised). J Endocrinol Metab
Diabetes S Afr 2012;17(2):S1-S95. http://www.semdsa.org.za/images/2012_SEMDSA_Guideline_ Diabetes S Afr 2012;17(2):S1-S95. http:
July_FINAL.pdf (accessed 22 April 2017).

9. Provincial Government Western Cape. Diabetes in pregnancy: A guideline for the management of diabetes and its complications from pre-conception to the postnatal period. 2010. https://scribd. hulkproxy.online/document/252323279/Diabetes-in-Pregnancy-Western-Cape-Guidelines (accessed 15 July 2016).

10. The HAPO Study Cooperative Research Group. Hyperglycaemia and adverse pregnancy outcomes. $\mathrm{N}$ Engl J Med 2008;358(19):1991-2002. http://dx.doi.org/10.1056/NEJMoa0707943

1. Malcolm J. Through the looking glass: Gestational diabetes as a predictor of maternal and offspring long-term health. Diabetes Metab Res Rev 2012;28(4):307-311. http://dx.doi.org/10.1002/dmrr.2275

12. Dasgupta K, Ross N, Meltzer S, et al. Gestational diabetes mellitus in mothers as a diabetes predictor in fathers: A retrospective cohort analysis. Diabetes Care 2015;38(9):e130-e131. http://dx.doi. in fathers: A retrospectiv
org $10.2337 /$ dc15-0855

13. Meek CL, Lewis HB, Patient C, et al. Diagnosis of gestational diabetes mellitus: Falling through the net. Diabetologica 2015;58(9):2003-2012. https://doi.org/10.1007/s00125-015-3647-z

14. O'Sullivan JB, Mahan, CM, Charles D, et al. Screening criteria for high risk gestational diabetic patients. Am J Obstet Gynecol 1973;116(7):895-900.
paris

15. Cosson E, Cussac-Pillegand C, Benbara A, et al. The diagnostic and prognostic performance of a selective screening strategy for gestational diabetes mellitus according to ethnicity in Europe. J Clin Endocrinol Metab 2014;99(3):996-1005. http://dx.doi.org/10.1210/jc.2013-3383

16. Visser GH, de Valk HW. Is the evidence strong enough to change the diagnostic criteria for gestational diabetes now? Am J Obstet Gynecol 2013;208(4):260-264. http://dx.doi.org/10.1016/j.ajog.2012.10.88

Accepted 15 February 2017. 